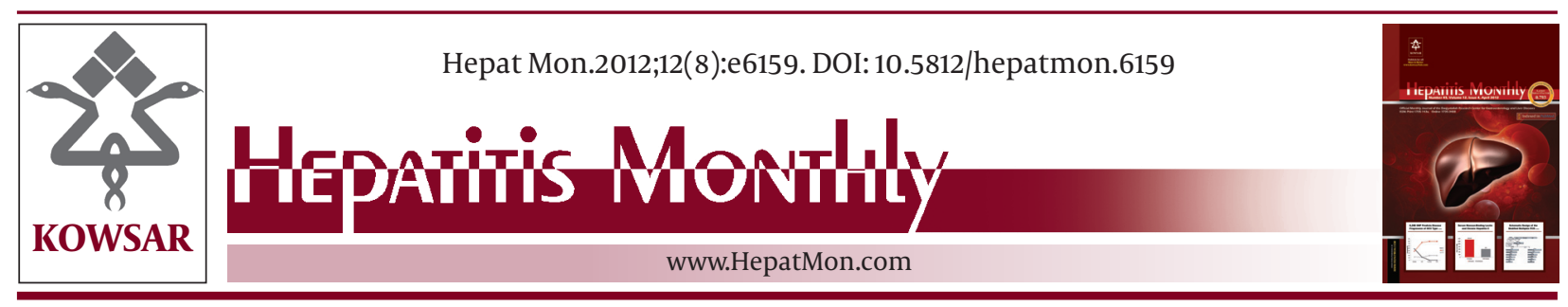

\title{
Mitoptosis, a Novel Mitochondrial Death Mechanism Leading Predominantly to Activation of Autophagy
}

\author{
Jaganmohan Reddy Jangamreddy ${ }^{1}$, Marek J. Los ${ }^{\circ}$ \\ ${ }^{1}$ Deptartment of Clinical and Experimental Medicine, Integrative Regenerative Medicine Center (IGEN), Division of Cell Biology, Linköping University, \\ Linkoping, Sweden
}

\begin{tabular}{l}
\hline A R T I C L E I N F O \\
\hline Article type: \\
Editorial \\
\hline Article history: \\
Received: 28 Feb 2012 \\
Revised: 10 Mar 2012 \\
Accepted: 23 Mar 2012 \\
\hline
\end{tabular}

Keywords:

Homeostasis

Cytochromes C

DNM1L Protein, Human

- Implication for health policy/practice/research/medical education:

The manuscript provides insight into the recently-discovered new form of cell death that may co-exist with autophagy, apoptosis or necorosis. The described below cellular extrusion of damaged mitochondria, may contribute to ethiology of some autoimmune diseases, as well as to the development of novel antiviral drugs that employ autophagy in their life-cycle.

- Please cite this paper as:

Jangamreddy JR, Los MJ. Mitoptosis, a Novel Mitochondrial Death Mechanism Leading Predominantly to Activation of Autophagy. Hepat Mon. 2012;12(8): e6159. DOI:10.5812/hepatmon.6159

Published by Kowsar Corp, 2012. cc 3.0.

Sometimes some members of multicellular organisms need to sacrifice for the good of the whole. Perhaps with the exception of immunomodulatory processes $(1,2)$, it is the intrinsic death pathway, often triggered by 053 (3-5), modulated by Bcl2-family members, and executed primarily by caspases that is most commonly employed to trigger cell death (6-8). Apoptotic or autophagic cell death is triggered by physical insults such as cold (9), natural compounds and their derivatives (10-12), viruses (13), or even disturbances within the cell cycle $(14,15)$. Apoptotic cell death is preceded by mitochondrial release of cytochrome c, which leads to increases in cytochrome c in serum (16). Mitochondria have been a cellular guest for millions of years and seamlessly transformed into a major functional cellular organelle. Until the last couple of decades, mitochondria were mainly viewed as powerhouses of the cell but more recent reports have indicated their crucial role in apoptosis, necrosis, and autophagy.
Opening of the permeability transition pore in the outer mitochondrial membrane, release of cytochrome c, and formation of apoptosomes is considered the turning point in apoptosis. Further studies showing the cellular localization and phenotypic and mechanistic modulations in mitochondria during cellular homeostasis, stress, and death, support the pivotal role of mitochondrial influenced cellular fate.

Thus, do mitochondria have the mechanisms to trigger host cell death or is the host directing the mitochondria depending on physiological needs? To what extent are mitochondria autonomous in their function and death? Recent reports about mitochondrial suicide (mitoptosis) and relocation of mitochondria to the nuclear periphery (thread-grain transition) may provide substantial answers to these basic questions. Two very interesting reviews (Skulachev, IUBMB Life 2000, and Skulachev, Apoptosis 2006) by Vladimir P. Skulachev elaborate the

\footnotetext{
*Corresponding author: Marek J. Los, IGEN Cell Biology Building, Linköping University IKE, Level 10, Linköping, Sweden. Tel: +46-101032787, Fax: +46-101032793, E-mail:marek.los@gmail.com

DOI:10.5812/hepatmon.6159

(C) 2012 Baqiyatallah Research Center for Gastroentrology and liver diseases; Published by Kowsar Corp.

This is an Open Access article distributed under the terms of the Creative Commons Attribution License(http://creativecommons.org/licenses/by/3.0), which permits unrestricted use, distribution, and reproduction in any medium, provided the original work is properly cited.
} 

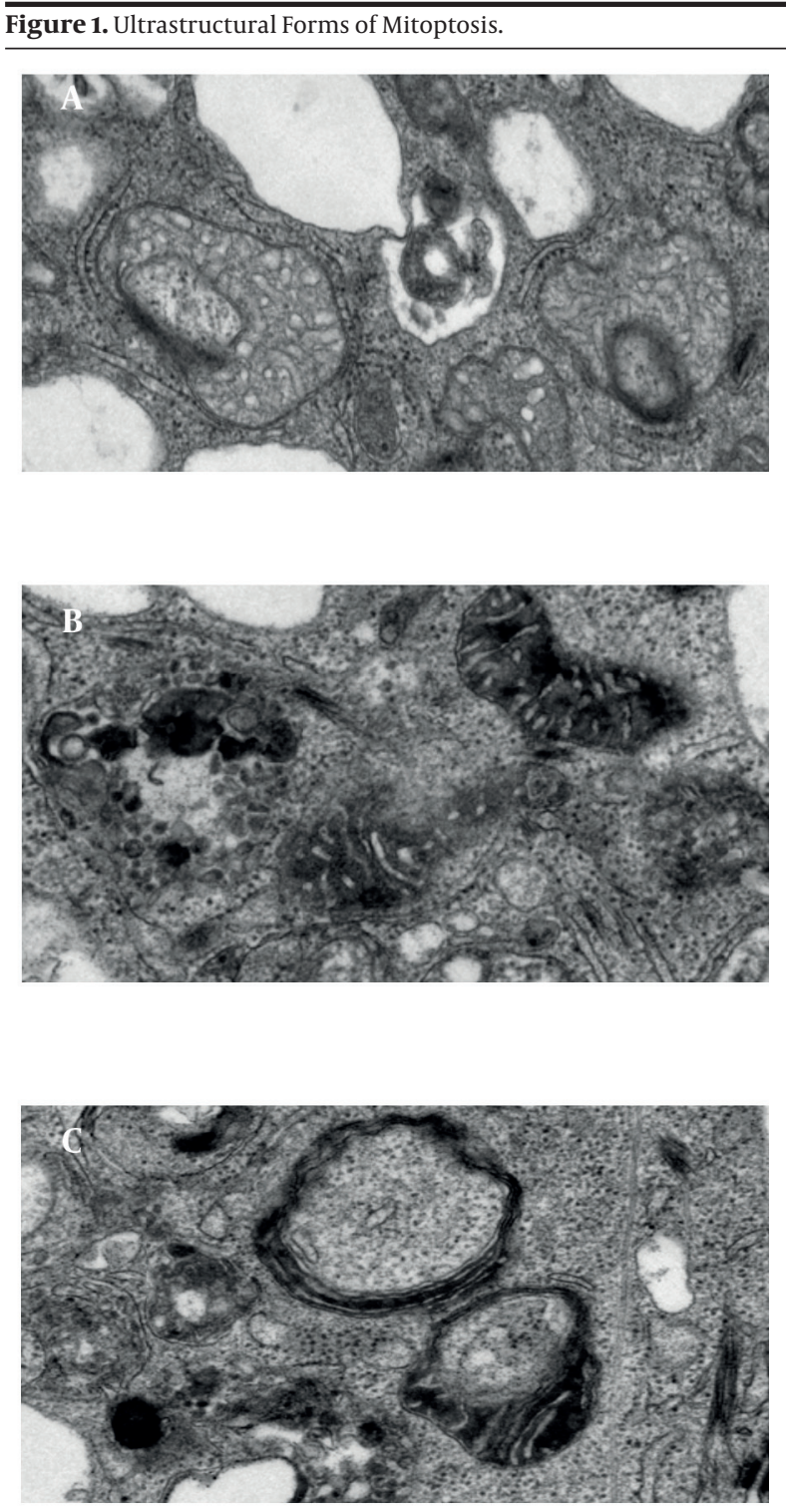

Mitoptosis was induced in PC3 prostate cancer cells Inner Membrane Mitoptosis (A) and in SKBR3 breast cancer cells by overnight treatment with salinomycin. Inner membrane mitoptosis (A) and outer membrane mitoptosis Outer Membrane Mitoptosis (B) in the apoptotic breast cancer cell and prostate cancer cell lines. We have also observed the third type of mitoptosis, which we have coined mitochondrial matrix mitoptosis Mitochondrial matrix Mitoptosis $(C)$ in which both membranes are degraded with the matrix.

fundamental understanding of mitochondrial suicide and the phenomenon of apoptosis and coined the term mitoptosis $(17,18)$. Mitoptosis takes various forms (Figure 1). Inner membrane mitoptosis may occur, in which only the internal matrix and cristae are degraded while the external mitochondrial envelope remains unaltered, or outer membrane mitoptosis may occur, in which only swollen internal cristae are detected as remnants. Furthermore, the fate of the degraded mitochondria may differ under different experimental conditions. The de- graded mitochondria may either become autophagosomes (predominant phenomenon observed in our lab), or mitoptotic bodies, which are extruded from the cell (19).

During "outer mitochondrial membrane mitoptosis", mitochondria undergo condensation, followed by swelling and fragmentation of cristae. Finally, the outer mitochondrial membrane bursts, and the vesicular remnants of cristae float into the cytoplasm. Mitochondrial swelling can be detected even at the fluorescence microscopy level. At high resolution, mitochondria appear round and swollen, before they disintegrate, rather than typically elongated and bean-shaped. During "inner mitochondrial membrane mitoptosis", the outer mitochondrial membrane remains intact and the cristae deteriorate. The inner membrane begins to coalesce, followed by rarefaction (loss of density) of the matrix, and finally degradation of cristae. We have often observed a third mixed form of mitoptosis in which mitochondria undergo condensation, followed by swelling and vesicular fragmentation of cristae, similar to "outer mitochondrial membrane mitoptosis", but instead of disruption of the outer mitochondrial membrane, the mitochondria become engulfed in autophagosomes. Thus, the fate of mitochondria inside stressed cells varies, and the study of mitoptosis in different model systems and the subcellular mechanisms underlying these processes still await conclusions. Mitoptosis occurs primarily due to the loss of membrane potential either because of the apoptotic signal or disruption in the respiratory chain, the inherent inability to synthesize major constituents, and failure to take up the nuclear-coded mitochondrial matrix proteins due to the loss of own membrane potential (18). Thus, it can be inferred that the apoptotic stimulus triggering loss of mitochondrial membrane potential is the major factor initiating mitoptosis. However, the initial apoptotic signal increases mitochondrial membrane potential during the early steps of apoptosis, eventually leading to loss of membrane potential. This initial increase in membrane potential is thought to be due to the ATP dependency of apoptosis, hence, the distantly located mitochondria (resulting from mitochondrial fission or thread-grain transition) need to be transfered to the nuclear surroundings to release apoptotic factors for nuclear transfer; thus, amplifying programmed cell death (18). This observation suggests that mitochondrial dysfunction and the production of reactive oxygen species (ROS) are major factors triggering mitoptosis. Such observations are further supported by studies using mitochondrial respiratory chain uncouplers and mitochondrial poisons in which overproduction of ROS could be observed without reductions in cellular ATP levels leading to mitoptosis (20). The specific removal of dysfunctional or ROS-overproducing mitochondria during apoptosis or mitoptosis is believed to be achieved by autophagy either by autophagosome formation (mitophagy) or by the formation of mitoptot- 
ic bodies that are subsequently released into the extracellular environment (19). The elimination of dysfunctional mitochondria is further supported by studies of cells treated with staurosporin, a common drug used to induce apoptosis, and by the use of pan-caspase inhibitors in which cells survive but lose their mitochondria (21). More recent studies on PINK1 and Drp1 in neural diseases suggest that dysfunctional mitochondria trigger autophagy and, thus, are eliminated (22). Thus, suggesting that mitochondrial dysfunction is a good enough reason for eliminating mitochondria and as Dr. Skulachev says, mitochondria follow the samurai's law; "it's better to die than to be wrong".

\section{Acknowledgments}

The authors apologize to all members of the cell death research community for not citing several excellent papers related to mitoptosis. This was simply due to a space limitation.

\section{Author's Contribution}

JJ \& JL jointly prepared the manuscript.

\section{Financial Disclosure}

None declared.

\section{Funding/Support}

ML and JR kindly acknowledge the core/startup support from Linköping University, the Integrative Regenerative Medicine Center (IGEN), and the Cancerfonden (CAN 2011/521).

\section{References}

1. Los M, van de Craen M, Penning CL, Schenk H, Westendorp M, Baeuerle PA, et al. Requirement of an ICE/Ced-3 protease for Fas/ Apo-1-1mediated apoptosis. Nature. 1995;371:81-3.

2. Los M, Wesselborg S, Schulze-Osthoff K. The role of caspases in development, immunity, and apoptotic signal transduction: lessons from knockout mice. Immunity.1999;10:629-39.

3. Ghavami S, Mutawe MM, Hauff K, Stelmack GL, Schaafsma D, Sharma P, et al. Statin-triggered cell death in primary human lung mesenchymal cells involves p53-PUMA and release of Smac and Omi but not cytochrome c. Biochim Biophys Acta. 2010;1803(4):452-67.

4. Ghavami S, Mutawe MM, Sharma P, Yeganeh B, McNeill KD, Klonisch T, et al. Mevalonate Cascade Regulation of Airway Mesenchymal Cell Autophagy and Apoptosis: A Dual Role for p53. PLoS One. 2011;6(1):e16523.

5. Vincent FC, Los MJ. New potential instrument to fight hepatocellular cancer by restoring p53. Hepat Mon. 2011;11(5):331-2.

6. Ghavami S, Eshraghi M, Kadkhoda K, Mutawe MM, Maddika S, Bay $\mathrm{GH}$, et al. Role of BNIP3 in TNF-induced cell death--TNF upregu- lates BNIP3 expression. Biochim Biophys Acta. 2009;1793(3):54660.

7. Ghavami S, Eshragi M, Ande SR, Chazin WJ, Klonisch T, Halayko AJ, et al. S100A8/A9 induces autophagy and apoptosis via ROSmediated cross-talk between mitochondria and lysosomes that involves BNIP3. Cell Res. 2010;20(3):314-31.

8. Ghavami S, Hashemi M, Ande SR, Yeganeh B, Xiao W, Eshraghi M, et al. Apoptosis and cancer: mutations within caspase genes. $J$ Med Genet. 2009;46(8):497-510.

9. Stroh C, Cassens U, Samraj AK, Sibrowski W, Schulze-Osthoff $\mathrm{K}$, Los M. The role of caspases in cryoinjury: caspase inhibition strongly improves the recovery of cryopreserved hematopoietic and other cells. Faseb J. 2002;16(12):1651-3.

10. Ghavami S, Asoodeh A, Klonisch T, Halayko AJ, Kadkhoda K, Kroczak TJ, et al. Brevinin-2R(1) semi-selectively kills cancer cells by a distinct mechanism, which involves the lysosomal-mitochondrial death pathway.J Cell Mol Med. 2008;12(3):1005-22.

11. Gokay O, Kuhner D, Los M, Gotz F, Bertsche U, Albert K. An efficient approach for the isolation, identification and evaluation of antimicrobial plant components on an analytical scale, demonstrated by the example of Radix imperatoriae. Anal Bioanal Chem. 2010;398(5):2039-47.

12. Mendoza FJ, Espino PS, Cann KL, Bristow N, McCrea K, Los M. Anti-tumor chemotherapy utilizing peptide-based approaches-apoptotic pathways, kinases, and proteasome as targets. Arch Immunol Ther Exp (Warsz). 2005;53(1):47-60.

13. Alavian SM, Ande SR, Coombs KM, Yeganeh B, Davoodpour P, Hashemi M, et al. Virus-triggered autophagy in viral hepatitis - possible novel strategies for drug development. J Viral Hepat. 2011;18(12):821-30.

14. Maddika S, Ande SR, Panigrahi S, Paranjothy T, Weglarczyk K, Zuse A, et al. Cell survival, cell death and cell cycle pathways are interconnected: Implications for cancer therapy. Drug Resist Updat. 2007;10(1-2):13-29.

15. Maddika S, Ande SR, Wiechec E, Hansen LL, Wesselborg S, Los M. Akt-mediated phosphorylation of CDK2 regulates its dual role in cell cycle progression and apoptosis. J Cell Sci. 2008;121(Pt 7):97988.

16. Barczyk K, Kreuter M, Pryjma J, Booy EP, Maddika S, Ghavami S, et al. Serum cytochrome c indicates in vivo apoptosis and can serve as a prognostic marker during cancer therapy. Int J Cancer. 2005;116(2):167-73.

17. Skulachev VP. Mitochondria in the programmed death phenomena; a principle of biology: "it is better to die than to be wrong". IUBMB Life. 2000;49(5):365-73.

18. Skulachev VP. Bioenergetic aspects of apoptosis, necrosis and mitoptosis. Apoptosis. 2006;11(4):473-85.

19. Lyamzaev KG, Nepryakhina OK, Saprunova VB, Bakeeva LE, Pletjushkina OY, Chernyak BV, et al. Novel mechanism of elimination of malfunctioning mitochondria (mitoptosis): formation of mitoptotic bodies and extrusion of mitochondrial material from the cell. Biochim Biophys Acta. 2008;1777(7-8):817-25.

20. Izyumov DS, Avetisyan AV, Pletjushkina OY, Sakharov DV, Wirtz KW, Chernyak BV, et al. "Wages of fear": transient threefold decrease in intracellular ATP level imposes apoptosis. Biochim Biophys Acta. 2004;1658(1-2):141-7.

21. Xue L, Fletcher GC, Tolkovsky AM. Mitochondria are selectively eliminated from eukaryotic cells after blockade of caspases during apoptosis. Curr Biol. 2001;11(5):361-5.

22. Dagda RK, Cherra SJ, 3rd, Kulich SM, Tandon A, Park D, Chu CT Loss of PINK1 function promotes mitophagy through effects on oxidative stress and mitochondrial fission. J Biol Chem. 2009;284(20):13843-55. 